\title{
Research on the Innovative Development of Multimedia Technology and Visual Communication Design Teaching
}

\author{
Yongxiao Liu \\ Baoshan University \\ Baoshan, Yunnan Province
}

\begin{abstract}
For visual communication teaching, innovation is one of the aspects that must be paid attention to in the development of teaching work, and it is also a necessary path to adapt to the needs of the current era and industrial development. Against the current backdrop of continuous development of multimedia technology, the development of visual communication design teaching activities needs to combine the current situation and technical characteristics to show more powerful innovation capabilities, introduce more innovative ideas, and better build a relevant professional talent pool to meet the demands. This paper analyzes the application advantages of multimedia and explores the relevant ideas of innovative development in combination with the multimedia technology.
\end{abstract}

Keywords-Innovative development; Multimedia technology; Visual communication design teaching

\section{INTRODUCTION}

In the digital age of the 21 st century, all communication and communication has been far faster than ever before due to the speed of its media, which has made people have to use more digital visual images other than words and sounds to communicate. And communicate. After the infiltration of digital information technology, the field of art design education in colleges and universities mainly presents the following characteristics: textbook multimedia, resource globalization, teaching individualization, learning autonomy and environmental virtualization. Faced with these characteristics, traditional teaching methods can no longer meet the needs of modern design teaching. As an important aspect of the application of digital modern educational technology in visual communication design education, it is to develop and develop multimedia teaching courseware that conforms to the rules of education and teaching. The purpose is to apply advanced information technology to optimize the education and teaching process, promote the level of intelligence in education, and improve the quality and effectiveness of education and teaching. Therefore, the application of multimedia technology in the teaching of visual communication design in colleges and universities has the advantage that traditional teaching methods can't match. Its high efficiency, large capacity, good audiovisual effects, fast and open information resources and interactive teaching functions provide excellent conditions for cultivating inquiry and creative design talents; updating educational concepts for teachers, improving teaching methods and promoting Design education has played a role that cannot be ignored in the development of high-level, diversified and informatized.

\section{THE APPLICATION ADVANTAGES OF MULTIMEDIA TECHNOLOGY IN VISUAL COMMUNICATION DESIGN TEACHING}

\section{A. The Multimediaization of Teaching Materials Enriches the Teaching Content of Visual Communication Design}

"Visual Communication Design" is a comprehensive discipline that combines application communication and art with graphic design as information carrier. The term "visual communication design" was coined by William Ad-dison Dwiggins (1880-1956) in 1922 and became popular in the 1960s. "At that time, the World Design Conference was held in Tokyo, Japan. Participants realized that in the ever-expanding video media, vision and video have existed as independent means of communication. They are different from other means of communication, but are more fully represented. The emergence and cognition of the name of visual communication design is that with the rapid development of science and technology in the world, the activities and performance contents of the original printed art design cannot meet the needs of society, in order to include Visual communication design emerges as a new information communication medium such as image (ie image)." According to our current understanding, the so-called visual communication design uses visual media as a carrier to express and convey information through visual symbols. At present, the concept of "visual communication design" has been adopted more widely in the design education community and society in China

Digital technology has made today's society a view era. Its cultural characteristics are the visualization, flattening, visualization and visualization of information. The visual information presented is vast, the time and space spans the past and the present, and the form of visual symbols is also dominated by planes. Expanding to three-dimensional or even four-dimensional forms, the communication medium is developed from printing, film and television to multimedia. The way of communication also develops from one-way information communication to interactive information communication. Therefore, in the actual teaching of the 
modern visual communication design classroom, it is necessary not only to break through the traditional teaching information transmission method, but also to link a very large amount of information. Especially when introducing the case teaching method to appreciate and analyze various visual works, the image quality of the works is required to be high, the number is large, and the forms of communication are diverse. However, due to its limitations, the existing visual textbooks are extremely limited in terms of type and quantity, and have shortcomings such as low precision, small size, silent, static and single information transmission.

In this case, the application of multimedia technology in the professional course teaching of visual communication design can timely and intuitively transmit knowledge to students in the form of images, sounds, animations, etc., not only to meet the requirements of students in the view era to obtain massive information, but also increase Large teaching capacity, to meet the characteristics and needs of visual communication design teaching, but also to attract students' attention, so that students have a learning interest and improve learning. It is also possible to update the cutting-edge knowledge and practical techniques at any time according to the actual teaching needs, improve the teaching level and teaching efficiency of teachers, and then adapt to the requirements of visual communication design teaching in the era of knowledge explosion.

\section{B. Multimediaization of Teaching Materials Optimizes the Teaching Mode of Visual Communication Design}

The quality of education is closely related to the success of a student. We know that the Internet is a new stage for visual communication design. Its infinite information resources, interactive graphics and high-speed and high-efficiency features have a huge impact on visual communication design. With the promotion and deepening of curriculum reform, the design curriculum resources are no longer limited to the art and design discipline itself, but will also be extended to the fields of nature, culture, society and economy.

Throughout the development of design education, it can be roughly divided into three educational modes: skill type, concept type and quality type. The teaching mode advocated by modern visual communication design is "quality", which is a brand-new model that aims to enhance the comprehensive ability of design. These comprehensive capabilities include design logic analysis capabilities, creative thinking skills, socio-cultural insights, and the ability to design expressions. Students are required not only to have deep professional knowledge and artistic accomplishment, but also to understand and master a wider range of interdisciplinary domain knowledge, to develop the knowledge structure from a single professional type to a cross-type and a three-dimensional type, and continuously enhance their comprehensive design capabilities. Due to the integration and interactivity of multimedia technology, the combination of material machine and human perception provides a possibility to improve the quality of teaching and the level of human-computer interaction. Multimedia technology has the characteristics of vividness, image, intuition, creativity and comprehensiveness in the course teaching, and these characteristics are difficult to achieve by traditional teaching methods. The use of a large number of course resources provided by multimedia technology can not only meet the needs of teacher teaching and student inquiry learning in a limited classroom time, but also utilize the network function of the multimedia computer system to break the time, space and teaching in the classroom and outside the classroom. Geographical restrictions, timely access to a large number of visual communication design materials and information, and actively guide students to carry out independent learning, improve their ability to self-learn and solve problems.

\section{THE KEY ISSUES OF MULTIMEDIA TECHNOLOGY IN THE TEACHING APPLICATION OF VISUAL COMMUNICATION DESIGN}

In human life, knowledge can be divided into explicit knowledge and tacit knowledge. Tacit knowledge is far more abundant than explicit knowledge. As Polanyi said, "We know more than we can say." In education, although the teaching content is mainly explicit knowledge, tacit knowledge is the source of understanding.

In the digital age, the cultural inheritance of education has been continuously expanded into technical transmission. Because of the narrative, interactivity and competitiveness of multimedia, the transmission of information, the way of communication between people and the way of understanding the world have changed. . The mass copying of images and the pervasiveness of the image are leading to the disappearance of the distinction between reality and image, and people are uncomfortable with the fact that they may enter a virtual world abstracted into a pile of numbers, data, symbols or graphics. Under the background of people's blind worship of digital technology, the authority of teachers is gradually replaced by computers, so that their influence on students' minds is gradually weakened, the humanistic value of education is gradually weakened; the reality of alienation from visual communication design education, The technique of light and heavy art makes the interpersonal relationship between teachers and students indifferent, and the morality of students declines, which leads to problems such as boredom of cultural knowledge learning.

We know that the teaching process of teachers is not only the process of imparting knowledge, but also the process of communication and communication between teachers and students. The development of digital information technology has caused a large number of perceptual and fleeting information to stimulate the cerebral cortex in a strong way, which has changed the information processing method of the mind; people are more inclined to accept dynamic and sensory information, thus avoiding abstract logical thinking. Abandoning the way of thinking that traces the essence; its own thoughts, morality, and individuality are not fully developed. Therefore, strengthening the humanities education with "people-oriented" as the core concept and strengthening the humanistic value orientation in digital education is the only way to solve this problem. In traditional teaching, the processing of teaching materials is mainly carried out from the cognitive dimension. In digital teaching design, it should be analyzed and processed from the emotional dimension; the information revolution has moved from science and technology to humanities, from tools to content. This new trend not only 
challenges the concept and method of visual communication design, but also puts forward new requirements for talent training to visual communication design education. Adhere to the principle of people-oriented, abandon the concept and behavior of technology first, create a humanized education environment, provide humanized educational resources, choose a humanized education method, and let multimedia technology truly exert its many advantages and become a visual communication design education. In addition, the main theme of higher education is "cultivating people" rather than "manufacturing". The main theme of China's higher education institutions is to train Chinese university students to serve both Chinese and innovative high-level talents. Therefore, in the visual communication design education teaching in the digital age, we must integrate "internationalization" and "nationalization", explore the humanistic education methods with Chinese national characteristics, and draw inspiration from them to make our country's visual communication design. Education has a situation of "international and western blending" and "hundred flowers bloom."

Since the development of educational informationization in colleges and universities, it has shifted from the previous construction focus to application, and fully applied the existing educational information facilities. Serving education and teaching activities is the key task of current visual communication design education. At present, the multimediaization of traditional classrooms in schools is a trend of development. The networking and digitization of future courses will be the direction of development, and the requirements for teachers' educational informationization will be higher and higher. However, there is a widespread education of teachers in education. Many teachers cannot control multimedia devices and cannot apply information technology to the classroom teaching of visual communication design. The benefits brought by multimedia cannot be fully utilized in teaching. In the process of using multimedia teaching, most teachers sit in front of the podium to operate the computer; students are not typing, or reading electronic documents on the screen. Many students do not have textbooks or class notes when they study theory classes. They are accustomed to using electronic documents instead of intensive reading of printed texts, and are willing to copy multimedia courseware to teachers instead of their own class notes, confusion and The concept of classroom teaching and distance education is blurred. In addition, in the selection of teaching content and resources, some teachers' multimedia courseware is completely a copy of the textbook, directly transferring the content of the textbook to the multimedia courseware locally, without the characteristics and advantages for multimedia and network information technology. The design of the teaching content, the new bottle of old drugs, but led to the students' resentment and resistance. There are other teachers who, on the contrary, put too much energy into the techniques of how to make beautiful courseware, and the content of these courseware is only an outline of traditional textbooks. It does not update multimedia capacity, efficiency and resources at any time. The advantages of playing it out are not practical. It is not difficult to see that media technology and informatization education free people from the hard work of acquiring knowledge and skills. It is easier to retrieve and acquire certain knowledge than ever before, but the convenience and effectiveness of information acquisition are not It is unified, which leads to the problem that the knowledge structure of students now has a width without depth.

\section{THE CONTENT OF TEACHING WORK SHOULD BE BASED ON THE PERSPECTIVE OF INNOVATION DEVELOPMENT}

First, the student's subjective status is clarified. Although the current level of educational technology is an important issue for the improvement of teaching technology, we still need to correctly recognize the basic status of students. In the process of applying multimedia technology, it is necessary to make appropriate adjustments to the teaching ideas, teaching contents, and teaching directions, and to incorporate more integrated ideas and methods. In combination with the subjective status of students, in the design and adjustment of teaching, it is necessary to "make a fuss" around the improvement of students' ability and quality, instead of using multimedia technology to "show off". Modern education For the cultivation of talents, the development of innovative work is carried out from an omnidirectional perspective. At the same time, the subjective status of students should be better defined so that the needs of innovation and development can be more clearly realized and implemented.

Second, create a more practical teaching system. In the current visual communication design teaching, the development of technology is to better improve the training level of talents. Only by better integrating technology and humanistic thinking, we can maximize the advantages of media technology and enhance vision. Communicate the overall level of design teaching. At this stage, teachers should make appropriate adjustments to their own teaching systems, integrate more teacher-student communication and communication, and build an educational environment with strong human characteristics, so that technology can be better weighed and applied. Balance of orientation. In the process of carrying out teaching activities, colleges and universities should also pay attention to the cultivation of the comprehensive quality of talents, let students break away from the previous learning characteristics, truly become the master of learning, and truly grow and develop in the new teaching system. In the construction and adjustment of the teaching system, teachers should also look to the future, make clear the needs of social-related employment positions, integrate teaching ideas with their own characteristics, and grasp the key points of talent cultivation. Teachers should actively change the previous teaching concepts, need to fully understand the role of new technologies in teaching, and link the teaching needs and teaching experience to the scientific and effective application of multimedia technology to teaching activities on the basis of positive changes in traditional teaching concepts. Among them, the application of new technology makes the classroom more colorful and active, which provides a positive auxiliary role for teaching.

Third, grasp the scale of multimedia technology application. For teaching activities, the protection of creativity requires us to constantly explore and think. This is also a kind of behavior with strong creativity. In order to achieve innovative development of teaching activities, teachers must scientifically 
grasp the application scale of multimedia technology. Although multimedia technology is applied in teaching, it can better conform to the characteristics of visual communication design teaching content and meet a variety of teaching needs. However, if the multimedia technology is applied too much and there is no strict scale for application, the overall teaching effect will be greatly increased. In the process of applying multimedia technology, we can't completely abandon the traditional teaching methods, but we must fully connect and unite with the modern teaching mode, and fully exert the characteristics and advantages of the two different teaching methods. Under the continuous development of modern technology, teachers themselves must maintain this clear mind and cognition and objectively apply multimedia technology. In the actual teaching work, teachers should continuously learn about information technology, actively participate in relevant teaching and training work, and let them have more control over the application of multimedia technology, so that they can start from the source and let multimedia technology communicate visually. Designing applications in the classroom is more reasonable.

\section{CONCLUSION}

In the process of current art design concept development and formal innovation, information digital technology plays an important role in promoting, which is also an important direction of the current art design development. Under this new trend, cultural relations have gradually undergone new changes. Visual communication design teaching itself needs to better apply new technologies, effectively combine the advantages of new technologies with themselves, and explore an educational model that is consistent with the characteristics of the times. In the process of application of multimedia technology, teachers need to continuously explore and research to improve the teaching quality of visual communication design.

\section{REFERENCES}

[1] Zhu Haikang. The Influence of Multimedia Technology on Library and Information Work and Its Application[J].Journal of the China Society for Scientific Information,2007(S1):50-54

[2] Zhao Jinyi. Application of Multimedia Technology in Library [J]. Book and Information, 2008 (3): 62-64.

[3] Yang Yang [1], Liu Qinghai [2]. Multimedia Technology and Electronic Publications [J]. Editorial Journal, 2008, 10(4): 209-211.

[4] Zhang Yanying. Developing and Utilizing Existing Resources to Develop Multimedia Technology of National Libraries[J]. Library Science Research, 2014(4): 91-92.

[5] Qi Shujuan. The Influence of Electronic Publications on Information Communication Mode [J]. Modern Information, 2001 (1): 21-22. 